\title{
CORRELACIONES GENÉTICAS Y FENOTÍPICAS ENTRE CARACTERÍSTICAS REPRODUCTIVAS DE VACAS LECHERAS ${ }^{1}$
}

\author{
Ángel Ríos-Utrera ${ }^{2}$, René Carlos Calderón-Robles ${ }^{3}$, Jorge Víctor Rosete-Fernández $z^{3}$, \\ Juvencio Lagunes-Lagunes ${ }^{4}$
}

\begin{abstract}
RESUMEN
Correlaciones genéticas y fenotípicas entre características reproductivas de vacas lecheras. El objetivo del presente trabajo fue estimar las correlaciones genéticas y fenotípicas de características reproductivas de 317 vacas Holstein Friesian y Suizo Pardo Americano. Las vacas nacieron y fueron criadas en condiciones subtropicales, en un periodo de 20 años (1986 a 2006), y fueron hijas de 116 sementales y 199 madres. El estudio se realizó en el sitio experimental Las Margaritas, en Hueytamalco, Puebla, México, el cual pertenece al Instituto Nacional de Investigaciones Forestales, Agrícolas y Pecuarias (INIFAP). Las características reproductivas estudiadas fueron: días a primer servicio después del parto (DPS), intervalo entre partos (IEP), días abiertos (DA), número de servicios por concepción (NSC) y tasa de gestación al primer servicio (TG). Las correlaciones genéticas fueron estimadas con un modelo animal simple para dos características (análisis bivariados), el cual incluyó el efecto genético aditivo individual como único efecto aleatorio. Los efectos fijos principales fueron: año de parto, época y raza. Los análisis se hicieron con máxima verosimilitud restringida, con un algoritmo libre de derivadas. En general, las características reproductivas estuvieron favorable y fuertemente asociadas genéticamente. Los estimadores de las correlaciones genéticas para DPS-IEP, DPS-DA, DPS-NSC, IEP-DA, IEP-NSC y DA-NSC fueron positivos $(0,89,0,89$, $0,25,0,90,0,59$ y 0,97 , respectivamente), mientras que todos los estimadores de las correlaciones genéticas que involucraron la tasa de gestación (DPS-TG, IEP-TG, DA-TG, NSC-TG) fueron negativos $(-0,45,-0,62,-0,72,-0,85)$. Los altos estimadores de las correlaciones genéticas entre IEP y DPS o DA indican que la selección para menos DPS o DA reduciría IEP.
\end{abstract}

Palabras clave: Asociaciones genéticas, días abiertos, intervalo entre partos, Holstein Friesian, Suizo Pardo Americano.

\begin{abstract}
Genetic and phenotypic correlations among reproductive traits of dairy cows. The objective of this work was to estimate the genetic and phenotypic correlations among fertility traits of 317 Holstein Friesian and Brown Swiss cows. Cows were born and reared under subtropical conditions, during a 20-year period (1986 to 2006), and were daughters of 116 sires and 199 dams. The study was carried out in Las Margaritas research station, in Hueytamalco, Puebla, México, which belongs to the Instituto Nacional de Investigaciones Forestales, Agrícolas y Pecuarias (INIFAP). Fertility traits studied were: days to first service after calving (DFS), calving interval (CI), days open (DO), number of services per conception (NSC) and conception rate at first service (CR). Genetic correlations were estimated with a two-trait animal model (bivariate analysis), which included individual additive genetic effect as a sole random effect. Main fixed effects were: calving year, calving season and breed of cow. Analyses were carried out with restricted maximum likelihood, using an algorithm free of derivatives. In general, fertility traits were favorably and strongly correlated genetically. Estimates of genetic correlations for DFS-CI, DFS-DO, DFS-NSC, CI-DO, CI-NSC, and DONSC were positive $(0,89,0,89,0,25,0,90,0,59$ and 0,97 , respectively), while all estimates of genetic correlations that included conception rate to first service (DFS-CR, CI-CR, DO-CR, NSC-CR) were negative $(-0,45,-0,62,-0,72,-0,85)$. The high estimates of genetic correlations between CI and DFS or DO indicate that selection for less DFS or DO would reduce $\mathrm{CI}$.
\end{abstract}

Key words: Genetic relationships, days open, calving interval, Holstein Friesian, Brown Swiss.

1 Recibido: 18 de marzo, 2010. Aceptado: 22 de noviembre, 2010. Este trabajo forma parte de un proyecto de investigación financiado por el Centro de Investigaciones Pecuarias del Estado de Puebla, A. C. (CIPEP, A. C.), México.

2 Campo Experimental La Posta, Instituto Nacional de Investigaciones Forestales, Agrícolas y Pecuarias (INIFAP), km 22.5 carretera VeracruzCórdoba, Paso del Toro, Municipio de Medellín de Bravo, Veracruz, México. 94277. Tel. (285) 596-0111. rios.angel@inifap.gob.mx., ariosu@hotmail.com

3 Sitio Experimental Las Margaritas, Instituto Nacional de Investigaciones Forestales, Agrícolas y Pecuarias (INIFAP), km 9.5 carretera HueytamalcoTenampulco, Hueytamalco, Puebla, México. 73580. Tel. (232) 118-8621. calderon.rene@inifap.gob.mx, rosete.jorge@inifap.gob.mx

4 Centro de Investigaciones Pecuarias del Estado de Puebla, A.C., km. 9.5 carretera Hueytamalco-Tenampulco, Hueytamalco, Puebla, México. 73580. Teléfono: (232) 118-8621. 


\section{INTRODUCCIÓN}

Con el propósito de aumentar la producción de leche, la selección genética de animales en los hatos lecheros, ha producido cambios en la fisiología reproductiva de las vacas. Comparadas con vacas lecheras de hatos tradicionales, las vacas lecheras de hatos tecnificados presentan: 1) intervalos más largos para ovular por primera vez, 2) mayor incidencia de anestros, 3) mayor incidencia de fases luteales anormales, 4) menores concentraciones de progesterona sanguínea, $5)$ menores concentraciones en sangre del factor de crecimiento parecido a la insulina, 6) mayores tasas de ovulación múltiple, 7) más partos gemelares, y 8) más pérdidas embrionarias (Lucy 2001). Este detrimento en la fertilidad obviamente sugiere que poca atención se le ha brindado a la fertilidad en el momento de la selección.

Es muy probable que la baja heredabilidad de las características reproductivas, la cual ha sido menor al 6\% en la gran mayoría de los estudios (Abdallah y McDaniel 2000, Castillo-Juarez et al. 2000, Dematawewa y Berger 1998, Haile-Mariam et al. 2003, Marti y Funk 1994, Hoeschele 1991), haya causado cierta incertidumbre respecto a si la selección de este tipo de características vale la pena. Sin embargo, algunos investigadores (Philipsson 1981, Hermas et al. 1987) han manifestado que existe suficiente variación genética aditiva y que, por lo tanto, los programas de selección deberían estar basados en la fertilidad de la vaca, en conjunto con la producción de leche y otras características, pues las ganancias económicas de los hatos lecheros también dependen de la eficiencia reproductiva, ya que entre más partos tenga una vaca, mayor será la producción de leche durante su vida productiva.

Las mediciones de fertilidad que son calculadas a partir de datos de inseminación se clasifican en dos categorías: mediciones de intervalo y binomiales. Ejemplos de mediciones de intervalo incluyen intervalo entre partos y días a primer servicio. Las binomiales usualmente incluyen características "éxito-fracaso" y se refieren a si la vaca ha o no ha concebido a la primera inseminación, o si ha o no ha concebido dentro de cierto número de días (e.g., tasa de no retorno a 60 ó 90 días).

Las tasas de no retorno se calculan frecuentemente, a preferencia de otras mediciones de fertilidad, ya que se pueden calcular para un mayor número de hembras. Sin embargo, el hecho de que una vaca no reciba una segunda inseminación dentro de un cierto número de días, no significa que la primera inseminación fue exitosa. Si además de la producción de leche, los animales van ser seleccionados genéticamente con base en alguna medición de fertilidad (índice de selección), es importante conocer la heredabilidad de esta última clase de características, así como la magnitud y el tipo de asociación que guardan entre ellas.

Con base en lo anterior, el objetivo del presente trabajo fue estimar las correlaciones genéticas y fenotípicas de características reproductivas de vacas Holstein Friesian y Suizo Pardo Americano mantenidas en condiciones subtropicales de México.

\section{MATERIALES Y MÉTODOS}

\section{Descripción del lugar donde se realizó el estudio}

El estudio se realizó en el sitio experimental Las Margaritas, perteneciente al Instituto Nacional de Investigaciones Forestales, Agrícolas y Pecuarias (INIFAP). El sitio experimental Las Margaritas está ubicado en el Municipio de Hueytamalco, en la sierra nororiente del estado de Puebla, México, a 500 msnm. Presenta un clima subtropical húmedo semicálido $\operatorname{Af}(\mathrm{c})$. La temperatura promedio anual es de $20,8^{\circ} \mathrm{C}$, la mínima de $15,3^{\circ} \mathrm{C}$ en invierno y la temperatura máxima es de $24,2^{\circ} \mathrm{C}$ en verano (junio a agosto). Además, presenta un periodo bien definido de lluvias de julio a octubre, y uno de baja temperatura con llovizna que inicia a finales de octubre y termina a finales de febrero.

\section{Población de estudio}

Para la realización del presente trabajo, se utilizó un total de 317 vacas de las razas Holstein y Suizo Pardo, las cuales fueron producidas con 116 sementales y 199 madres. Éstos fueron usados a través de inseminación artificial (principalmente) y monta natural. Las hembras nacieron en un periodo de 20 años, de 1986 a 2006, en el sitio experimental Las Margaritas.

\section{Manejo reproductivo}

El manejo reproductivo de las vaquillas se inició cuando alcanzaron aproximadamente $350 \mathrm{~kg}$, momento en el cual se realizóla primera inspección de los genitales internos mediante palpación rectal. Posteriormente, 
esta valoración se realizó rutinariamente cada 15 días para determinar la existencia de posibles problemas reproductivos. La detección de calores (estros) se realizó una hora en la mañana (de 06:00 a 07:00 h) y otra en la tarde (de 17:00 a 18:00 h), con el apoyo de un toro con pene desviado. Las hembras en celo fueron inseminadas de la manera convencional. Las que presentaban celo en la mañana fueron inseminadas en la tarde, y las que presentaban celo en la tarde se inseminaron al siguiente día por la mañana. El diagnóstico de gestación se realizó a partir de los 45 días posteriores a la última inseminación.

\section{Alimentación}

Las vacas se mantuvieron en pastoreo rotacional en potreros con zacate Estrella de África (Cynodon plectostachyus). Los periodos de ocupación de los potreros fueron de dos a tres días, y los de descanso fueron de 35 a 40 días, dependiendo de la época del año, con una carga animal de 2,5 unidades animal por hectárea al año. Durante la época de estiaje (noviembre a marzo), las vacas recibieron de 20 a $30 \mathrm{~kg} / \mathrm{animal} /$ día de Caña Japonesa (Saccharum sinense). Además, las vacas en lactancia recibieron durante el ordeño $3,5 \mathrm{~kg}$ de un alimento concentrado comercial ( $16 \%$ de proteína cruda y $70 \%$ de total de nutrientes digestibles) al día, mientras que las vacas secas recibieron $2 \mathrm{~kg}$ del mismo tipo de alimento al día.

\section{Características analizadas}

Las correlaciones genéticas fueron estimadas para cinco características reproductivas: 1) días a primer servicio después del parto (DPS), definido como el número de días que transcurrieron desde el parto a la primera inseminación registrada; 2) número de servicios por concepción (NSC); 3) días abiertos (DA), que se definió como el número de días que transcurrieron del parto a la concepción; 4) intervalo entre partos (IEP), medido como el número de días que transcurrieron entre dos partos consecutivos; y 5) tasa de gestación al primer servicio (TG), la cual se codificó como 0 si la hembra recibió más de un servicio. Por el contrario, la tasa de gestación se codificó como 1 si la hembra quedó gestante con el primer servicio de inseminación artificial o monta natural.

\section{Estadísticas descriptivas}

Para la edición de la información, el intervalo entre partos se limitó de 300 a 550 días, se eliminaron los registros que se encontraban fuera de este intervalo. Intervalos menores a 300 días probablemente indican aborto, mientras que los mayores a 550 días podrían indicar una duración anormal de la lactancia. Los días a primer servicio después de parto y los días abiertos fueron restringidos de 21 a 250 días, ya que valores fuera de este intervalo pudieron ser fisiológicamente anormales o registrados erróneamente.

Las estadísticas descriptivas y parte de la estructura de la información, por característica, después de haber aplicado estos criterios de edición, se presentan en el Cuadro 1. El intervalo del número de registros analizados para las características evaluadas fue de 781 (para intervalo entre partos) a 1119 (para días a primer servicio después del parto). En promedio, 73 días después del parto las vacas estuvieron aptas para ser inseminadas por primera vez, con un intervalo promedio entre dos partos consecutivos de 389 días. El

Cuadro 1. Estadísticas descriptivas para características reproductivas de vacas Holstein Friesian y Suizo Pardo Americano mantenidas en condiciones subtropicales de 1986 a 2006 en Hueytamalco, Puebla, México.

\begin{tabular}{lccccc}
\hline & DPS & IEP & DA & NSC & TG \\
\hline Número de observaciones & 1119 & 781 & 963 & 1104 & 1116 \\
Media & 73 & 389 & 101 & 2,04 & 0,45 \\
Desviación estándar & 45 & 57 & 54 & 1,31 & 0,50 \\
Coeficiente de variación & 62 & 15 & 53 & 64 & 110 \\
Valor mínimo & 21 & 301 & 25 & 1 & 0 \\
Valor máximo & 250 & 549 & 250 & 7 & 1 \\
Número de hijas & 317 & 249 & 283 & 298 & 298 \\
Número de sementales & 116 & 100 & 107 & 112 & 112 \\
Número de madres & 199 & 166 & 180 & 188 & 188 \\
Número de animales en el & 580 & 580 & 580 & 580 & 580 \\
pedigrí & & & & & \\
\hline
\end{tabular}

DPS $=$ días a primer servicio después del parto; $\mathrm{IEP}=$ intervalo entre partos (días); DA= días abiertos; $\mathrm{NSC}=$ número de servicios por concepción; TG= tasa de gestación al primer servicio (0 ó 1). 
número de hijas con registros útiles varió de 249 a 317. El pedigrí fue el mismo para todas las características estudiadas y consistió de 580 animales, incluyendo padres sin genealogía y madres sin registros reproductivos ni genealógicos.

\section{Estructura de la información}

En el caso de días a primer servicio después del parto, $58,6 \%(\mathrm{n}=68)$ del total de sementales utilizados tuvo dos hijas o más, mientras que $41,4 \%(n=48)$ de los sementales tuvo una sola hija (Cuadro 2). Para intervalo entre partos, 58\% ( $\mathrm{n}=58)$ de los sementales tuvo dos hijas o más, mientras que $42 \%(n=42)$ de los sementales tuvo una sola hija. El número promedio de hijas con registros por semental fue de 2,7 y 2,5, para

Cuadro 2. Número de sementales que tuvieron de una hasta diecinueve hijas con vacas Holstein Friesian y Suizo Pardo, para las características con el mayor (días a primer servicio) y el menor número de registros (intervalo entre partos), en un hato criado de 1986 a 2006 en Hueytamalco, Puebla, México

\begin{tabular}{lccc}
\hline Característica & $\begin{array}{c}\text { No. de se- } \\
\text { mentales }\end{array}$ & $\begin{array}{c}\text { No. de } \\
\text { hijas }\end{array}$ & $\begin{array}{c}\text { No. total } \\
\text { de hijas }\end{array}$ \\
\hline Días a primer servicio & 48 & 1 & 48 \\
& 33 & 2 & 66 \\
& 9 & 3 & 27 \\
& 4 & 4 & 16 \\
& 9 & 5 & 45 \\
& 3 & 6 & 18 \\
Intervalo entre partos & 3 & 7 & 21 \\
& 3 & 9 & 27 \\
& 3 & 10 & 30 \\
& 1 & 19 & 19 \\
\hline Total & 116 & & 317 \\
& 29 & 1 & 42 \\
& 10 & 2 & 58 \\
& 4 & 4 & 30 \\
& 6 & 5 & 16 \\
& 1 & 6 & 30 \\
& 4 & 7 & 28 \\
& 2 & 8 & 16 \\
& 1 & 9 & 9 \\
& 1 & 14 & 14 \\
\hline & 100 & & 249 \\
& & &
\end{tabular}

días a primer servicio después del parto e intervalo entre éstos, respectivamente.

\section{Análisis estadísticos}

\section{Análisis preliminares}

Antes de la estimación de los parámetros genéticos, se realizaron análisis estadísticos preliminares para cada característica reproductiva para determinar qué efectos fijos eran fuentes de variación importantes, para lo cual se utilizó el procedimiento Mixed de SAS (Statistical Analysis System; Littell et al. 1996). Los efectos fijos incluidos en el modelo completo fueron: raza de la vaca (Holstein Friesian, Suizo Pardo Americano), año de parto $(1990,1991, \ldots, 2007)$, época de parto (noviembre-febrero; marzo-junio; julio-octubre), las interacciones de primer orden que se derivan de estos efectos principales, y la edad de la vaca al parto como covariable, tanto en forma lineal, como cuadrática. Además, el modelo completo preliminar incluyó el efecto aleatorio del semental anidado dentro de raza.

Para determinar los modelos definitivos, se realizaron análisis secuenciales para cada característica, removiendo del modelo completo las interacciones y/o las covariables que no resultaban significativas a una $\mathrm{P}$ $<0,05$. El modelo definitivo para número de servicios por concepción estuvo integrado por raza de la vaca, año y época de parto. Adicionalmente, el modelo definitivo para intervalo entre partos y tasa de gestación a primer servicio incluyó la interacción año de parto $\mathrm{x}$ época de parto, mientras que para días abiertos, en lugar de la interacción año de parto x época de parto, el modelo definitivo incluyó la interacción raza de la vaca $x$ año de parto. El modelo definitivo para días a primer servicio después del parto estuvo formado por los efectos principales (raza, año y época), la interacción año de parto $\mathrm{x}$ época de parto y la covariable edad de la vaca al parto, en forma lineal y cuadrática. Todos los modelos definitivos incluyeron el efecto aleatorio del semental anidado dentro de raza.

\section{Análisis bivariados con máxima verosimilitud restringida}

Los componentes de (co)varianza se estimaron por medio de máxima verosimilitud restringida libre de derivadas (Smith y Graser 1986), utilizando el 
programa MTDFREML (Boldman et al. 1995). Se hicieron análisis bivariados con un modelo animal que incluyó los efectos principales de raza de la vaca, año de parto y época de parto, las interacciones de primer orden (de dos factores) y las covariables que fueron significativas para cada característica en los análisis preliminares, así como el efecto genético aditivo individual, que fue considerado como un efecto aleatorio.

El modelo animal puede ser descrito de la siguiente manera:

$$
\mathrm{Y}=\mathrm{X} \beta+\mathrm{Za}+\mathrm{e}, \text { donde }
$$

$\mathrm{Y}$ es el vector de registros,

$\beta$ es el vector de efectos fijos (raza de la vaca, año de parto y época de parto),

a es un vector desconocido de efectos aleatorios genéticos aditivos directos,

e es un vector desconocido de efectos aleatorios del ambiente temporal y

$\mathrm{X}, \mathrm{y} \mathrm{Z}$ son matrices conocidas de incidencia que relacionan los registros con $\beta$ y a, respectivamente.

Los valores esperados $(E)$ y las (co)varianzas $(V)$ para los efectos aleatorios del modelo animal fueron:

$$
E\left[\begin{array}{l}
a \\
e
\end{array}\right]=\left[\begin{array}{l}
0 \\
0
\end{array}\right], \quad V\left[\begin{array}{l}
a \\
e
\end{array}\right]=\left[\begin{array}{cc}
G_{0} \otimes A & 0 \\
0 & R_{0} \otimes I
\end{array}\right]
$$

donde

$$
G_{0}=\left[\begin{array}{ll}
\sigma_{a i}^{2} & \sigma_{a i j} \\
\sigma_{a i j} & \sigma_{a j}^{2}
\end{array}\right], \quad R_{0}=\left[\begin{array}{cc}
\sigma_{e i}^{2} & \sigma_{e i j} \\
\sigma_{e i j} & \sigma_{e j}^{2}
\end{array}\right],
$$

$\otimes$ es el producto directo o de Kronecker.

$A$ es la matriz de Wright de parentescos aditivos entre todos los animales en el pedigrí,

$\sigma_{a i}^{2}$ es la varianza genética aditiva individual para la característica $i$,

$\sigma_{a j}^{2}$ es la varianza genética aditiva individual para la caraterística $j$,

$\sigma_{a i j}^{2}$ es la covarianza genética entre las características $i$ y $j(i \neq j)$,

$\sigma_{e i}^{2}$ es la varianza residual para la característica $i$, $\sigma^{2}{ }_{e j}^{e}$ es la varianza residual para la característica $j$,

$\sigma_{e i j}^{2}$ es la covarianza residual entre las características $i$ y $j(i \neq j)$.
I es una matriz identidad de tamaño igual al número de observaciones.

\section{Valores preliminares y convergencia}

Los valores iniciales de la varianza genética aditiva individual y la residual, la covarianza genética y la covarianza residual que se usaron en los análisis bivariados, se basaron en valores obtenidos a partir de análisis previos univariados. Se asumió que la convergencia fue obtenida cuando la varianza de los valores de menos dos veces el logaritmo de la verosimilitud en el simplex fue menor que $10^{-8}$. Después de que el programa convergió por primera vez, se realizaron varios reinicios para verificar que la convergencia no se efectuó en un local mínimo, sino en un global máximo.

Los estimadores de las correlaciones genéticas $\left(r_{g}\right)$ se obtuvieron a partir de los estimadores de los componentes de (co)varianza con la siguiente ecuación:

$$
r_{g i, j}=\sigma_{g i, j} / \sigma_{g i} \sigma_{g j}, \text { donde }
$$

$i \mathrm{y} j$,

$\sigma_{g i, j}=$ covarianza genética entre las características

$\sigma_{g i}=$ desviación estándar genética de la característica $i, \mathrm{y}$ rística $j$.

$\sigma_{g j}=$ desviación estándar genética de la caracte-

Como se mencionó anteriormente, el número de observaciones fue diferente para cada una de las cinco características reproductivas estudiadas (Cuadro 1). Desafortunadamente, cuando se realizan análisis multivariados para características que tienen diferente número de observaciones, el programa MTDFREML no calcula errores estándar para estimadores de correlaciones genéticas. Para poder obtener los errores estándar de los estimadores de las correlaciones genéticas, se realizaron análisis adicionales con información reeditada (menos información), de tal manera que cada hembra contó con información, en cada repetición, para cada característica involucrada en un análisis bivariado. Sin embargo, debido a la poca información disponible, los errores estándar obtenidos a partir de estos análisis fueron grandes, por lo cual no se muestran en el presente trabajo. 


\section{RESULTADOS Y DISCUSIÓN}

\section{Correlaciones residuales}

Los estimadores de las correlaciones residuales entre las cinco características reproductivas analizadas se muestran en el Cuadro 3. Los estimadores de las correlaciones residuales de días abiertos con intervalo entre partos, y de tasa de gestación con número de servicios por concepción fueron altos, lo que sugiere que los errores de medición dentro de cada par de características estaban relacionados. Por el contrario, los estimadores de las correlaciones residuales de días a primer servicio con número de servicios por concepción y tasa de gestación fueron bajos, e indican que los residuales de los días a primer servicio fueron independientes de los residuales del número de servicios por concepción y de los de la tasa de gestación. Los estimadores de las correlaciones residuales de días a primer servicio con intervalo entre partos, de intervalo entre partos con número de servicios por concepción, y de días abiertos con tasa de gestación, fueron moderados.

\section{Correlación genética entre días a primer servicio e intervalo entre partos}

Los estimadores de las correlaciones genéticas (arriba de la diagonal) y fenotípicas (debajo de la diagonal) se presentan en el Cuadro 4. El estimador de la correlación para días a primer servicio e intervalo entre partos indica que estas dos características reproductivas están positiva y estrechamente asociadas genéticamente. Este resultado era de esperarse, ya que el intervalo entre partos es una medida de tiempo compuesta que depende parcialmente de los días a primer servicio, así como de la duración de la gestación. Kadarmideen et al. (2000) obtuvieron un estimador de la correlación genética entre días a primer servicio e intervalo entre partos con un valor igual $(0,89)$

Cuadro 3. Estimadores de correlaciones residuales de características reproductivas de vacas Holstein Friesian y Suizo Pardo Americano mantenidas en condiciones subtropicales de 1986 a 2006 en Hueytamalco, Puebla, México.

\begin{tabular}{lcccc}
\hline & $\begin{array}{c}\text { Días a primer } \\
\text { servicio después } \\
\text { del parto }\end{array}$ & $\begin{array}{c}\text { Intervalo entre } \\
\text { partos (días) }\end{array}$ & $\begin{array}{c}\text { Días } \\
\text { abiertos }\end{array}$ & $\begin{array}{c}\text { Número de } \\
\text { servicios por } \\
\text { concepción }\end{array}$ \\
\hline Días a primer servicio después del parto & & & & \\
Intervalo entre partos (días) & 0,55 & 0,90 & & \\
Días abiertos & 0,59 & 0,51 & 0,59 & $-0,71$ \\
Número de servicios por concepción & $-0,11$ & $-0,32$ & $-0,36$ & \\
Tasa de gestación al primer servicio (0 ó 1) & 0,17 & & & \\
\hline
\end{tabular}

Cuadro 4. Estimadores de correlaciones genéticas (arriba de la diagonal) y fenotípicas (debajo de la diagonal) de características reproductivasa de vacas Holstein Friesian y Suizo Pardo Americano mantenidas en condiciones subtropicales de 1986 a 2006 en Hueytamalco, Puebla, México.

\begin{tabular}{lccccc}
\hline & $\begin{array}{c}\text { Días a primer } \\
\text { servicio des- } \\
\text { pués del parto }\end{array}$ & $\begin{array}{c}\text { Intervalo entre } \\
\text { partos (días) }\end{array}$ & $\begin{array}{c}\text { Días } \\
\text { abiertos }\end{array}$ & $\begin{array}{c}\text { Número de } \\
\text { servicios por } \\
\text { concepción }\end{array}$ & $\begin{array}{c}\text { Tasa de gesta- } \\
\text { ción al primer } \\
\text { servicio (0 ó 1) }\end{array}$ \\
\hline Días a primer servicio después del parto & - & 0,89 & 0,89 & 0,25 & $-0,45$ \\
Intervalo entre partos (días) & 0,57 & - & 0,90 & 0,59 & $-0,62$ \\
Días abiertos & 0,63 & 0,90 & - & 0,97 & $-0,72$ \\
Número de servicios por concepción & $-0,09$ & 0,49 & 0,56 & - & $-0,85$ \\
Tasa de gestación al primer servicio (0 ó 1) & 0,15 & $-0,32$ & $-0,35$ & $-0,71$ & - \\
\hline
\end{tabular}


al obtenido en el presente estudio. Similarmente, muchos otros trabajos, como los realizados por Silva et al. (1992), Grosshans et al. (1997), Pryce et al. (1997), Veerkamp et al. (2001) y GonzálezRecio y Alenda (2005), reportaron estimadores de correlaciones genéticas con valores altos, de 0,80 a 0,93 . Sin embargo, en algunos estudios (Schneeberger y Hagger 1986, Haile-Mariam et al. 2003, Pryce et al. 1998) se ha encontrado que la correlación genética entre los días a primer servicio y el intervalo entre partos no es alta, sino moderada $(0,39,0,55$ y 0,56 , respectivamente).

\section{Correlación genética entre días a primer servicio y días abiertos}

Los días a primer servicio después del parto estuvieron alta y positivamente correlacionados genéticamente con los días abiertos. Hansen et al. (1983), Mäntysaari y Van Vleck (1989), Silva et al. (1992), Grosshans et al. (1997) y González-Recio y Alenda (2005) obtuvieron valores similares a los del presente estudio para la correlación genética entre días a primer servicio después del parto y días abiertos $(0,84,0,84$, $0,86,0,84,0,82$, respectivamente) (Cuadro 3 ). Por el contrario, en un estudio realizado a finales de los ochenta (Raheja et al. 1989), se obtuvieron estimadores de correlaciones genéticas positivos y relativamente bajos al analizar información de vacas con una $(0,28)$, dos $(0,21)$ y tres lactancias $(0,12)$. Otros estudios (Berger et al. 1981, Schneeberger y Hagger 1986, Moore et al. 1990), sin embargo, sugieren que los días a primer servicio están positiva y moderadamente correlacionados genéticamente $(0,54,0,45,0,37)$ con los días abiertos.

\section{Correlación genética entre días a primer servicio y número de servicios por concepción}

De todas las asociaciones genéticas estudiadas, aquella entre los días a primer servicio después del parto y el número de servicios por concepción resultó ser la más débil. Este resultado sugiere que las vacas con periodos más largos del parto al primer servicio tendieron a requerir más inseminaciones una vez que se empezaron a aparear. Los estimadores de la correlación genética para días a primer servicio y número de servicios por concepción reportados en la literatura científica son muy variables, causando cierta incertidumbre sobre la magnitud, así como de la dirección de la correlación. Estos estimadores van desde altos y negativos (-0,74; Núñez et al. 2006, -0,63; Schneeberger y Hagger 1986) hasta moderados y positivos $(0,52$; Hansen et al. 1983; 0,38; Berger et al. 1981), pasando por estimadores muy similares a cero $(-0,01$; Kadarmideen et al. 2000; -0,02, Raheja et al. 1989), que indican la ausencia de asociación genética, y estimadores bajos (0,12; Biffani et al. 2005, 0,13, Roxström et al. 2001, 0,15, VanRaden et al. 2004), que sugieren una débil asociación. Por su parte, Berger et al. (1981) y Moore et al. (1990) obtuvieron estimadores similares a los del presente trabajo $(0,27$ y 0,28 , respectivamente) para vacas Holstein de primer parto.

\section{Correlación genética entre días a primer servicio y tasa de gestación}

En contraste con los estimadores discutidos previamente, el estimador de la correlación genética entre los días a primer servicio después del parto y la tasa de gestación fue moderado y negativo, con un valor de $-0,45$. La mayoría de los estimadores de la correlación genética entre estas dos características reproductivas hallados en la literatura, coinciden en dirección, o signo, con el estimador del presente estudio, excepto los estimadores positivos $(0,41,0,15)$ reportados por Faust et al. (1989) y Pryce et al. (1997). Sin embargo, de los estimadores con signo negativo encontrados en la literatura, algunos son de mayor magnitud que el estimador obtenido en el presente estudio, como los reportados por Haile-Mariam et al. (2003) y González-Recio y Alenda (2005); pero otros son de menor magnitud, como los reportados por Pryce et al. (1998) y Kadarmideen et al. $(2000,2003)$.

\section{Correlación genética para intervalo entre partos y días abiertos}

Los días abiertos estuvieron favorable y altamente correlacionados genéticamente con el intervalo entre partos, sugiriendo que estas dos características reproductivas son, en gran medida, genéticamente equivalentes; es decir, muchos de los genes que afectan el intervalo entre partos son los mismos que afectan los días abiertos, lo que se conoce como efecto pleiotrópico (Berger et al. 1981). El presente resultado corrobora 
los hallazgos de diversos investigadores (Schneeberger y Hagger 1986, Silva et al. 1992, Grosshans et al. 1997, Kadarmideen et al. 2003, González-Recio y Alenda 2005), quiénes han reportado estimadores de correlaciones genéticas casi perfectos $(0,98,0,96$, $0,98,0,97$ y 0,99 , respectivamente) para intervalo entre partos y días abiertos. Por el contrario, en un estudio realizado en condiciones subtropicales en el estado de Florida (Estados Unidos de América; Campos et al. 1994), también se estimaron correlaciones genéticas positivas con información de vacas Holstein $(0,52)$ y Jersey $(0,68)$, pero lejanas a 1 .

\section{Correlación genética para intervalo entre partos y número de servicios por concepción}

El análisis conjunto del intervalo entre partos y el número de servicios por concepción indica que la asociación genética entre estas dos características es positiva y moderada (Cuadro 3), de manera similar a lo reportado por Biffani et al. (2005), para vacas Holstein italianas $(0,61)$, por Wall et al. (2003), para vacas Holstein inglesas $(0,61)$, y por Schneeberger y Hagger (1986), para vacas con diferentes porcentajes de genes Suizo Pardo Americano $(0,54)$. En un estudio realizado en España (González-Recio y Alenda 2005) también se obtuvo un estimador de la correlación genética positivo, pero alto $(0,89)$, para intervalo entre partos y número de servicios por concepción. Por el contrario, en un estudio mexicano un poco más reciente (Núñez et al. 2006), se encontró que este tipo de asociación fue débil $(0,28)$. A esta serie de estudios se puede agregar el trabajo publicado por Kadarmideen et al. (2000), quienes reportaron un estimador de 0,41, el cual, en conjunto con los demás estimadores reportados en la literatura, nos permite apreciar lo variable que es la magnitud de los estimadores de la correlación genética entre estas dos características.

\section{Correlación genética para intervalo entre partos y tasa de gestación}

En el presente estudio se encontró que la tasa de gestación estuvo negativamente correlacionada genéticamente con el intervalo entre partos, así como lo está con los días a primer servicio. Sin embargo, el estimador de la correlación genética para la tasa de gestación y el intervalo entre partos fue 1,4 veces mayor que el estimador para la tasa de gestación y los días a primer servicio. El estimador de la correlación genética para intervalo entre partos y tasa de gestación obtenido en el presente estudio fue mayor que el estimador correspondiente $(-0,30)$ calculado con información de vacas Holstein que participaron en uno de los programas nacionales de control de registros del Reino Unido (Kadarmideen et al. 2000). Pryce et al. (1998) y Veerkamp et al. (2000), por el contrario, informaron que el estimador de la correlación genética para intervalo entre partos y tasa de gestación fue de alta magnitud $(-0,81$ y $-0,84$, respectivamente), mientras que el estimador correspondiente $(-0,59)$ reportado por González-Recio y Alenda (2005) sugiere que el intervalo entre partos y la tasa de gestación a primer servicio estaban moderadamente correlacionados genéticamente, de manera similar a lo encontrado por nosotros.

\section{Correlación genética entre días abiertos y número de servicios por concepción}

El número de servicios por concepción estuvo favorable y altamente correlacionado genéticamente con los días abiertos, sugiriendo que mecanismos biológicos comunes controlan estas dos características. Este resultado implica que la selección a largo plazo de vacas y vaquillas que requieren un menor número de inseminaciones para quedar gestantes, permitiría reducir de manera significativa el intervalo del parto a la concepción. El estimador de la correlación genética para días abiertos y número de servicios por concepción publicado en el presente trabajo es similar a los estimadores correspondientes $(0,89$ y 0,94$)$ reportados por Moore et al. (1990) y González-Recio y Alenda (2005). Sin embargo, el presente estimador es sustancialmente mayor que los bajos estimadores obtenidos por Raheja et al. (1989) para vacas Holstein con una $(0,14)$, dos $(0,09)$ y tres lactancias $(0,04)$, los cuales sugieren que los días abiertos y el número de servicios por concepción están favorable, pero débilmente correlacionados genéticamente. Por su parte, los trabajos de Berger et al. (1981), Schneeberger y Hagger (1986), Grosshans et al. (1997) y Dematawewa y Berger (1998) también coinciden en que la asociación genética entre estas dos características es favorable, pero a un nivel moderado $(0,45,0,51,0,44,0,51)$. 


\section{Correlación genética entre días abiertos y tasa de gestación}

El estimador de la correlación genética para tasa de gestación y días abiertos resultó ser altamente favorable (negativo), lo que implica que la selección de hembras bovinas con una mayor capacidad para quedar gestantes podría resultar en una reducción de los días abiertos. Al parecer, existen pocos estudios disponibles en la literatura científica que reportan estimadores de la correlación genética entre días abiertos y tasa de gestación. Sin embargo, los pocos estudios hallados (Kadarmideen et al. 2003, González-Recio y Alenda 2005) coinciden en que la asociación genética entre estas dos características es favorable, de moderadamente alta $(-0,74)$ a casi perfecta $(-0,94)$.

\section{Correlación genética entre número de servicios por concepción y tasa de gestación}

Además de la fuerte asociación, el presente estudio revela que la tasa de gestación estuvo negativamente correlacionada genéticamente con el número de servicios por concepción, así como lo estuvo con los días a primer servicio, el intervalo entre partos y los días abiertos. Todos los estudios encontrados en la literatura (Oltenacu et al. 1991, Kadarmideen et al. $2000,2003)$ muestran una fuerte y negativa correlación genética $(-0,98,-0,99,-0,92)$ entre el número de servicios por concepción y la tasa de gestación, lo cual concuerda con lo hallado en la presente investigación.

En general, las cinco características reproductivas analizadas estuvieron alta y favorablemente correlacionadas genéticamente entre ellas, lo que revela la presencia de efectos pleiotrópicos. Estos resultados muestran que los estimadores de correlaciones genéticas para características reproductivas obtenidos con vacas lecheras en condiciones subtropicales, en general no difieren de los obtenidos con vacas lecheras en climas templados. Los estimadores de las correlaciones genéticas de días a primer servicio con intervalo entre partos, días abiertos y número de servicios por concepción, de intervalo entre partos con días abiertos y número de servicios por concepción, y de días abiertos con número de servicios por concepción fueron todos positivos, mientras que los estimadores de las correlaciones genéticas para los pares de características reproductivas que incluyeron tasa de gestación, fueron todos negativos. Estos resultados implican, por ejemplo, que la selección de hembras bovinas de la raza Holstein y Suizo Pardo que requieren menos días para ser inseminadas y/o gestadas conduciría a una disminución del intervalo entre partos.

\section{LITERATURA CITADA}

Abdallah, JM; McDaniel, BT. 2000. Genetic parameters and trends of milk, fat, days open, and body weight after calving in North Carolina experimental herds. Journal of Dairy Science 83:1364-1370.

Berger, PJ; Shanks, RD; Freeman, AE; Laben, RC. 1981. Genetic aspects of milk yield and reproductive performance. Journal of Dairy Science 64:114-122.

Biffani, S; Canavesi, R; Samore, AB. 2005. Estimates of genetic parameters for fertility traits of Italian HolsteinFriesian cattle. Stocarstvo 59(2):145-153.

Boldman, KG; Kriese, LA; Van Vleck, LD; Van Tassell, CP; Kachman, SD. 1995. A manual for use of MTDFREML: A set of programs to obtain estimates of variances and covariances [Draft]. ARS, USDA, Washington, DC.

Campos, MS; Wilcox, CJ; Becerril, CM; Diz, A. 1994. Genetic parameters for yield and reproductive traits of Holstein and Jersey cattle in Florida. Journal of Dairy Science 77:867-873.

Castillo-Juarez, H; Oltenacu, PA; Blake, RW. 2000. Effect of herd environment on the genetic and phenotypic relationships among milk yield, conception rate, and somatic cell score in Holstein cattle. Journal of Dairy Science 83:807-814.

Dematawewa, CMB; Berger, PJ. 1998. Genetic and phenotypic parameters for 305-day yield, fertility, and survival in Holsteins. Journal of Dairy Science 81: 2700-2709.

Faust, MA; McDaniel, BT; Robison, OW. 1989. Genetics of reproduction in primiparous Holsteins. Journal of Dairy Science 72:194-201.

González-Recio, O; Alenda, R. 2005. Genetic parameters for female fertility traits and a fertility index in Spanish dairy cattle. Journal of Dairy Science 88:3282-3289.

Grosshans, T; Xu, ZZ; Burton, LJ; Johnson, DL; Macmillan, KL. 1997. Performance and genetic parameters for fertility of seasonal dairy cows in New Zealand. Livestock Production Science 51:41-51.

Haile-Mariam, M; Morton, JM; Goddard, ME. 2003. Estimates of genetic parameters for fertility traits of Australian Holstein-Friesian cattle. Animal Science 76:35-42. 
Hansen, LB; Freeman, AE; Berger, PJ. 1983. Yield and fertility relationships in dairy cattle. Journal of Dairy Science 66:293-305.

Hermas, SA; Young, CW; Rust, JW. 1987. Genetic relationships and additive genetic variation of productive and reproductive traits in Guernsey dairy cattle. Journal of Dairy Science 70:1252-1257.

Hoeschele, I. 1991. Additive and nonadditive genetic variance in female fertility of Holsteins. Journal of Dairy Science 74:1743-1752.

Kadarmideen, HN; Thompson, R; Coffey, MP; Kossaibati, MA. 2003. Genetic parameters and evaluations from single- and multiple-trait analysis of dairy cow fertility and milk production. Livestock Production Science 81:183-195.

Kadarmideen, HN; Thompson, R; Simm, G. 2000. Linear and threshold model genetic parameters for disease, fertility and milk production in dairy cattle. Animal Science 71:411-419.

Littell, RC; Milliken, GA; Stroup, WW; Wolfinger, RD. 1996. SAS System for Mixed Models. SAS Inst., Inc. Cary, NC, US.

Lucy, MC. 2001. Reproductive loss in high-producing dairy cattle: Where will it end? Journal of Dairy Science 84: 1277-1293.

Mantysaari, E; Van Vleck, LD. 1989. Estimation of genetic parameters for production and reproduction in Finnish Ayrshire cattle. Journal of Animal Science 72:23752386.

Marti, CF; Funk, DA. 1994. Relationship between production and days open at different levels of herd production. Journal of Dairy Science 77:1682-1690.

Moore, RK; Kennedy, BW; Schaeffer, LR; Moxley, JE. 1990. Relationships between reproduction traits, age and body weight at calving, and days dry in first lactation Ayrshires and Holsteins. Journal of Dairy Science 13:835-842.

Núñez, SG; Montaldo, HH; Román-Ponce, S; Ruiz-López, F; Castillo-Juárez, H; Román-Ponce, H; Castañeda, OG. 2006. (Co)variances for milk production and reproduction traits in a multibreed cattle population in the humid tropics of Mexico. In 8th World Congress on Genetics Applied to Livestock Production. Belo Horizonte, MG, Brazil. CD-ROM.

Oltenacu, PA; Frick, A; Lindhe B. 1991. Relationship of fertility to milk yield in Swedish cattle. Journal of Dairy Science 74:264-268.
Philipsson, J. 1981. Genetic aspects of female fertility in dairy cattle. Livestock Production Science 8:307-319.

Pryce, JE; Esslemont, RJ; Thompson, R; Veerkamp, RF; Kossaibati, MA; Simm, G. 1998. Estimation of genetic parameters using health, fertility and production data from a management recording system for dairy cattle. Animal Science 66:577-584.

Pryce, JE; Veerkamp, RF; Thompson, R; Hill, WG; Simm, G. 1997. Genetic aspects of common health disorders and measures of fertility in Holstein Friesian dairy cattle. Animal Science 65:353-360.

Raheja, KL; Burnside, EB; Schaeffer, LR. 1989. Relationships between fertility and production in Holstein dairy cattle in different lactations. Journal of Dairy Science 72:2670-2678.

Roxström, A; Strandberg, E; Berglund, B; Emanuelson, U; Philipsson, J. 2001. Genetic and environmental correlations among female fertility traits, and between the ability to show oestrus and milk production in dairy cattle. Acta Agriculturae Scandinavica, Section A, Animal Science 51:192-199.

Schneeberger, M; Hagger, C. 1986. Relationship of fertility parameters with lactation yield in cows of various crossbreeding levels. 3rd World Congress on Genetics Applied to Livestock Production. Lincoln, Nebraska, USA. 11:107-112.

Silva, HM; Wilcox, CJ; Thatcher, WW; Becker, RB; Morse, D. 1992. Factors affecting days open, gestation length, and calving interval in Florida dairy cattle. Journal of Dairy Science 75:288-293.

Smith, SP; Graser, HU. 1986. Estimating variance components in a class of mixed models by restricted maximum likelihood. Journal of Dairy Science 69: 1156-1165.

VanRaden, PM; Sanders, AH; Tooker, ME; Miller, RH; Norman, HD; Kuhn, MT; Wiggans, GR. 2004. Development of a national genetic evaluation for cow fertility. Journal of Dairy Science 87:2285-2292.

Veerkamp, RF; Koenen, EPC; De Jong, G. 2001. Genetic correlations among body condition score, yield, and fertility in first-parity cows estimated by random regression models. Journal of Dairy Science 84:23272335.

Wall, E; Brotherstone, S; Woolliams, JA; Banos, G; Coffey, MP. 2003. Genetic evaluation of fertility using direct and correlated traits. Journal of Dairy Science 86: 4093-4102. 